\title{
Oestrogen receptor polymorphisms and late-life depression
}

Joanne Ryan, Jacqueline Scali, Isabelle Carrière, Karine Peres, Olivier Rouaud, Pierre-Yves Scarabin, Karen Ritchie and Marie-Laure Ancelin

\section{Background}

Evidence suggests a role for oestrogen in depression but the involvement of oestrogen receptor polymorphisms remains unknown.

\section{Aims \\ To determine the association between oestrogen receptor polymorphisms and late-life depression and the modifying effect of hormone treatment.}

\section{Method}

Depression was assessed using the Mini-International Neuropsychiatric Interview, according to DSM-IV criteria and the Centre for Epidemiologic Studies - Depression Scale. The association between oestrogen receptor $\alpha$ and $\beta$ (ER- $\alpha$ and ER- $\beta$ ) polymorphisms with severe depression was examined in 6017 community-dwelling elderly people using multivariate logistic regression.

\section{Results}

In women, the ER- $\alpha$ rs2234693 and rs9340799

polymorphisms were significantly associated with the risk of late-life depression. The $A$ allele of ER- $\beta$ rs1256049 increased the risk of depression, but only for non-current users of hormone treatment. In men, only the ER- $\beta$ rs4986938 polymorphism showed a weak association with depression risk.

\section{Conclusions}

Oestrogen receptor polymorphisms are associated with severe late-life depression risk in women only.

\section{Declaration of interest}

None.
Depression is a major public health problem with high prevalence rates worldwide and an increased risk of comorbidity and mortality, especially in elderly people. Family studies have provided evidence that there is a genetic component to depressive disorders, although only a small number of candidate genes have been identified. ${ }^{1}$ Several lines of evidence suggest a role for oestrogen in depression. Depression results from a disruption in normal brain neurochemistry, including depletion in the levels of serotonin, and oestrogen has been shown to modulate neurotransmitter turnover and enhance serotonergic activity. ${ }^{2}$ Numerous epidemiological studies support these observations, linking oestrogen with depressed mood and antidepressant response (see Ancelin et al for a review ${ }^{3}$ ). Oestrogen-containing hormone treatment is also effective in improving the depressed mood of perimenopausal women, ${ }^{4}$ although its use in older postmenopausal women remains more controversial. However, given that the actions of oestrogen occur in large part through intracellular activation of oestrogen receptors (ER- $\alpha$ and ER- $\beta$ ), it is surprising that very few studies have examined whether oestrogen receptor polymorphisms can modify the risk of depression. Polymorphisms of these receptors have been associated previously, although not consistently, with oestradiol levels, ${ }^{5}$ vasomotor symptoms ${ }^{6}$ and other brain disorders such as Alzheimer's disease. ${ }^{7,8}$ Genetic variation in oestrogen receptors may also influence a person's susceptibility to developing depression and may modify oestrogen signalling and thus the effect of hormone treatment on mood, but this has not been examined previously. This current study aimed to investigate the association between severe late-life depression and five ER- $\alpha$ and ER- $\beta$ polymorphisms. Given the lack of data in this field, we did not hypothesise which genotypes would be most frequent in participants with depression. Analysis was stratified by gender so that individual associations in men and women could be identified, and the potential modifying effect of hormone treatment use in women could be evaluated.

\section{Method}

\section{Study population}

This analysis uses data collected at baseline from the Three City (3C) Study, an ongoing multicentre longitudinal study involving the French cities Bordeaux, Dijon and Montpellier. ${ }^{9}$ Recruitment of the cohort took place between 1999 and 2001, with eligible participants (aged over 65 years and non-institutionalised) being randomly selected from the electoral rolls in the three cities. In total $37 \%$ of the individuals contacted agreed to participate and were administered interviews by trained staff and underwent a number of clinical examinations. The study protocol was approved by the Ethical Committee of the University Hospital of Kremlin-Bicêtre (France) and participants provided written informed consent. Of the 9097 dementia-free participants initially recruited in the 3C Study, those who were not assessed for current and previous psychiatric symptomatology $(n=953)$ or who did not provide blood samples for genotyping analysis $(n=1291)$ could not be included in this analysis. We also excluded participants with incomplete genotyping data $(n=237)$ or missing data concerning the key covariates $(n=599)$, such that all of the analyses presented are based on the same population sample. Participants excluded from this analysis were significantly more likely to have current depression $\left(\chi_{1}^{2}=73.9, P<0.0001\right)$ and were more likely to be female $\left(\chi^{2}{ }_{1}=38.7, P<0.001\right)$; however, there was no significant difference in terms of the distribution of oestrogen receptor polymorphism genotypes.

\section{Measures of depression}

The Mini-International Neuropsychiatry Interview (MINI), a standardised psychiatric examination that has been validated in the general population, ${ }^{10}$ was used for the diagnosis of current and previous major depressive disorder, according to DSM-IV 
criteria. ${ }^{11}$ Severity of depressive symptoms was assessed with the Centre for Epidemiology Studies - Depression Scale (CES-D). ${ }^{12}$ Participants with a DSM-IV diagnosis of current major depressive disorder or those scoring above the clinical cut-off for 'probable' depression $(C E S-D \geqslant 23),{ }^{13}$ were classified as having current severe depression in this analysis. Current use of antidepressants, validated by presentation of the prescription or the medication itself, was also considered as a covariate in the analysis.

\section{Oestrogen receptor polymorphisms}

Fasting venous blood samples were taken from the participants at baseline. Blood was collected on ethylene diamine tetraacetic acid (EDTA) and DNA was extracted from white blood cells (Puregene kit, Qiagen, France) and stored at $-80^{\circ} \mathrm{C}$. Genotyping was performed by Kbiosciences (Hoddesdon, Hertfordshire, UK) using their competitive allele-specific polymerase chain reaction (PCR) single-nucleotide polymorphism (SNP) genotyping system (KASPar). The amplified PCR products were analysed by fluorescence scanning in a BMG labtech Pherastar scanner and the results were interpreted with their KlusterCaller 1.1 software for Windows (www.kbiosciences.co.uk). The error rate for the KASPar assay system is less than $0.3 \%$.

Five SNPs were examined that have shown potential causal associations with diseases and other hormone-related health outcomes in some previous studies, including Alzheimer's disease, ${ }^{7,8}$ cognitive function, ${ }^{14}$ cardiovascular disease, ${ }^{15,16}$ bone mineral density, ${ }^{17,18}$ breast cancer, ${ }^{19}$ vasomotor symptoms ${ }^{6}$ and oestradiol levels. ${ }^{20}$ These are: ER- $\alpha$ rs2234693 (otherwise known as $P v u \mathrm{II}$ ) and rs9340799 (XbaI), ER- $\beta$ rs1256049 (AluI), rs4986938 (RsaI) and rs1271572 (in the promoter region of the gene).

\section{Other measures}

When participants joined the study, information was obtained on sociodemographic and lifestyle characteristics, as well as overall health. Body mass index (BMI) was calculated as weight $(\mathrm{kg})$ divided by the height squared $\left(\mathrm{m}^{2}\right)$. Participants unable to complete at least two tasks from either the Instrumental Activities of Daily Living (IADL) ${ }^{21}$ or the Activities of Daily Living (ADL) ${ }^{22}$ scales, were classified as having physical limitations. Cognitive impairment was defined as having a Mini-Mental State Examination (MMSE) ${ }^{23}$ score of less than 26 and questionnaires concerning sleeping habits were used to define insomnia. ${ }^{24}$ Current use of hormone treatment at the time of the baseline interview was validated by presentation of the prescription or the medication itself.

Information on the participant's health was obtained through detailed medical questionnaires, a complete inventory of all drugs used within the preceding month and from fasting blood samples. These questionnaires included their history of vascular diseases (angina pectoris, myocardial infarction, stroke, cardiovascular surgery, bradycardia or palpitations), other chronic illnesses (asthma, diabetes (fasting glucose $\geqslant 7.0 \mathrm{mmol} / \mathrm{l}$ or reported treatment), hypercholesterolemia (total cholesterol $\geqslant 6.2 \mathrm{mmol} / \mathrm{l}$ ), hypertension (resting blood pressure $\geqslant 160 / 95 \mathrm{mmHg}$ or treated) and thyroid problems) or cancer diagnosis within the previous 2 years. Participants were classified as having comorbidity if they suffered from vascular disease, more than one chronic illness or a recent cancer.

\section{Statistical analysis}

A $\chi^{2}$ test was used to compare the observed allele frequencies with those expected under the Hardy-Weinberg equilibrium. The association between baseline sociodemographic and clinical variables with both depression and oestrogen receptor polymorphisms was examined using $t$-tests, ANOVA and $\chi^{2}$ tests. Due to the statistically significant interactions between gender and depression, all subsequent analyses were undertaken separately for males and females. Genotype frequencies of the oestrogen receptor polymorphisms were compared for participants with depression and those without using logistic regression models. Adjustment was made for covariates that were significantly associated with depression in this sample and that remained significant in the final multivariate models. The potential interaction between oestrogen receptor polymorphisms and the use of oestrogen-containing hormone treatment in women was also considered, based on our a priori hypothesis that oestrogen receptor polymorphisms could mediate the effect of oestrogen on depression. There was no indication of collinearity between the covariates in the adjusted models. We used SAS version 9.1 for Windows for all of the analyses and all tests were two-tailed, with a significance level of $P<0.05$.

\section{Results}

\section{Participants' characteristics}

Baseline characteristics of the 6017 participants are summarised in Table 1 . They ranged in age from 65 to 96 years with a mean of 73 years. Men and women differed significantly on all sociodemographic and health variables examined, with the exception of age. Women were significantly more likely to use antidepressants, to have current depressive symptoms and to have a current or previous diagnosis of major depressive disorder (Table 1). Overall, 564 participants were diagnosed with current severe depression (CES-D $\geqslant 23$ or current major depressive disorder), with a higher prevalence rate in women compared with men $\left(12.9 \%\right.$ v. $4.4 \%$ respectively, $\left.\chi_{1}^{2}=123, P<0.001\right)$.

\section{Polymorphism frequencies according to depression status}

The overall distribution of genotypes in both genders was not significantly different from those predicted by the HardyWeinberg equilibrium, except in the case of the ER- $\beta$ rs1271572 polymorphisms in women $\left(\chi^{2}{ }_{1}=5.7, P=0.02\right)$. The ER- $\alpha$ polymorphisms are known to be in strong linkage disequilibrium with one another, ${ }^{16}$ as are the three ER- $\beta$ polymorphisms examined. ${ }^{16}$ Genotype frequencies for each of the oestrogen receptors according to the participant's depression status are given in Table 2. There was no significant difference in the genotype distribution between men and women, although women were more likely to be heterozygous for ER- $\beta$ rs4986938 (49.6\% of women overall had the GA genotype compared with $46.6 \%$ of men, $\chi_{2}^{2}=5.7, P=0.06$ ). For both genders, the frequency of the $A A$ genotype for ER- $\beta$ rs1256049 was very small so these participants were grouped with those heterozygous $G A$ for subsequent analysis.

\section{Oestrogen receptor polymorphisms and depression}

The results of the multivariate logistic regression analyses for the associations between oestrogen receptor polymorphisms and depression are shown in Table 3. In men the only borderline significant association was a 1.7 times increase in current severe depression with the $A A$ versus the $G G$ genotype of ER- $\beta$ rs4986938. None of the other polymorphisms showed any significant association with depression in men. 
Table 1 Comparison between the characteristics of 6017 elderly community dwelling men and women, who participated in the 3C Study

\begin{tabular}{|c|c|c|c|c|c|}
\hline \multirow[b]{2}{*}{ Characteristic } & \multirow[b]{2}{*}{ Men $(n=2492)$} & \multirow[b]{2}{*}{ Women $(n=3525)$} & \multicolumn{3}{|c|}{ Test for gender difference } \\
\hline & & & $t$-test & $\chi^{2}$ (d.f.) & $P$ \\
\hline Age, years: mean (s.d.) & $73.4(4.9)$ & $73.5(4.9)$ & -0.89 & & 0.37 \\
\hline Body mass index, $\mathrm{kg} / \mathrm{m}^{2}$ : mean (s.d.) & $26.3(3.4)$ & $25.3(4.2)$ & 9.2 & & $<0.001$ \\
\hline$\geqslant 12$ years schooling, $\%$ & 38.8 & 24.9 & & $133(1)$ & $<0.001$ \\
\hline Married or living with others, \% & 83.2 & 48.1 & & 767 (1) & $<0.001$ \\
\hline Current heavy drinker, $\geqslant 24 \mathrm{~g}$ each day: $\%$ & 34.6 & 4.1 & & 956 (1) & $<0.001$ \\
\hline Heavy smoker, 10 pack-years: \% & 8.3 & 3.8 & & $57.1(1)$ & $<0.001$ \\
\hline Physical activity limitations, \% & 5.3 & 7.5 & & $11.2(1)$ & $<0.001$ \\
\hline At least three current medications, $\%$ & 48.0 & 56.1 & & $38.0(1)$ & $<0.001$ \\
\hline Cognitive impairment, \% & 21.7 & 26.4 & & $17.7(1)$ & $<0.001$ \\
\hline Insomnia, \% & 15.1 & 31.2 & & $204(1)$ & $<0.001$ \\
\hline History of cerebro- and cardiovascular disease, $\%$ & 22.3 & 11.4 & & $128(1)$ & $<0.001$ \\
\hline Comorbidity, ${ }^{a} \%$ & 50.8 & 46.9 & & $9.1(1)$ & 0.003 \\
\hline Current use of hormone treatment, $\%$ & - & 15.3 & & - & - \\
\hline Current use of antidepressants, \% & 3.4 & 7.8 & & $50.0(1)$ & $<0.001$ \\
\hline Severe depressive symptoms, CES-D $\geqslant 23: \%$ & 4.3 & 12.2 & & $113(1)$ & $<0.001$ \\
\hline Current major depressive disorder, \% & 0.6 & 2.0 & & $18.1(1)$ & $<0.001$ \\
\hline Previous major depressive disorder, \% & 6.9 & 14.4 & & $83.6(1)$ & $<0.001$ \\
\hline Centre, \% & & & & $0.72(2)$ & 0.70 \\
\hline Bordeaux & 22.3 & 22.0 & & & \\
\hline Dijon & 53.0 & 54.1 & & & \\
\hline Montpellier & 24.7 & 23.9 & & & \\
\hline
\end{tabular}

Among women however, those homozygous $C C$ for the ER- $\alpha$ rs2234693 polymorphism were $40 \%$ less likely to have current severe depression compared with homozygous TT women. The findings concerning the rs9340799 polymorphism were almost identical, with women having the $G G$ genotype significantly less likely to have late-life depression compared with women with the $A A$ genotype. In terms of the ER- $\beta$, women with at least one $A$ allele of the rs1256049 polymorphism were more likely to

Table 2 Oestrogen receptor polymorphism genotype frequencies according to current depression status

\begin{tabular}{|c|c|c|c|c|}
\hline \multirow[b]{2}{*}{ Polymorphism and genotype } & \multicolumn{2}{|c|}{ Men, \% } & \multicolumn{2}{|c|}{ Women, \% } \\
\hline & $\begin{array}{l}\text { No depression } \\
\quad(n=2382)\end{array}$ & $\begin{array}{l}\text { Severe current depression } \\
\qquad(n=110)\end{array}$ & $\begin{array}{l}\text { No depression } \\
\quad(n=3071)\end{array}$ & $\begin{array}{l}\text { Severe current depression } \\
\qquad(n=454)\end{array}$ \\
\hline \multicolumn{5}{|l|}{ ER- $\alpha$ rs2234693 } \\
\hline TT & 29.8 & 32.7 & 30.0 & 33.9 \\
\hline CT & 50.8 & 48.2 & 49.9 & 51.1 \\
\hline$C C$ & 19.4 & 19.1 & 20.1 & 15.0 \\
\hline \multicolumn{5}{|l|}{ ER- $\alpha$ rS9340799 } \\
\hline$A A$ & 41.6 & 48.2 & 41.5 & 44.5 \\
\hline GA & 46.4 & 38.2 & 46.5 & 46.7 \\
\hline GG & 12.0 & 13.6 & 12.0 & 8.8 \\
\hline \multicolumn{5}{|l|}{ ER- $\beta$ rs1256049 } \\
\hline GG & 91.4 & 90.9 & 92.2 & 89.7 \\
\hline GA & 8.4 & 8.2 & 7.7 & 10.1 \\
\hline$A A$ & 0.2 & 0.9 & 0.1 & 0.2 \\
\hline \multicolumn{5}{|l|}{ ER- $\beta$ rs4986938 } \\
\hline GG & 38.1 & 31.8 & 36.3 & 34.1 \\
\hline GA & 46.5 & 47.3 & 49.2 & 52.0 \\
\hline$A A$ & 15.4 & 20.9 & 14.5 & 13.9 \\
\hline \multicolumn{5}{|l|}{ ER- $\beta$ rs1271572 } \\
\hline GG & 32.6 & 31.8 & 32.7 & 30.6 \\
\hline TG & 49.2 & 52.7 & 49.8 & 54.6 \\
\hline TT & 18.2 & 15.5 & 17.5 & 14.8 \\
\hline
\end{tabular}


Table 3 Adjusted logistic regression models for the associations between oestrogen receptor polymorphisms and current severe depression $^{\mathrm{a}}$

\begin{tabular}{|c|c|c|c|c|}
\hline \multirow[b]{2}{*}{ Polymorphism and genotype } & \multicolumn{2}{|c|}{ Men } & \multicolumn{2}{|c|}{ Women } \\
\hline & Odds ratio $(95 \% \mathrm{Cl})$ & $P$ & Odds ratio $(95 \% \mathrm{Cl})$ & $P$ \\
\hline \multicolumn{5}{|l|}{ ER- $\alpha$ rs2234693 } \\
\hline TT & 1 & & 1 & \\
\hline$C T$ & $0.89(0.57-1.40)$ & 0.62 & $0.88(0.69-1.11)$ & 0.27 \\
\hline$C C$ & $0.85(0.48-1.51)$ & 0.58 & $0.61(0.44-0.84)$ & 0.003 \\
\hline \multicolumn{5}{|l|}{ ER- $\alpha$ rs9340799 } \\
\hline$A A$ & 1 & & 1 & \\
\hline$G A$ & $0.72(0.47-1.10)$ & 0.13 & $0.90(0.72-1.13)$ & 0.37 \\
\hline$G G$ & $0.99(0.53-1.83)$ & 0.97 & $0.60(0.41-0.88)$ & 0.009 \\
\hline \multicolumn{5}{|l|}{ ER- $\beta$ rs1256049 } \\
\hline GG & 1 & & 1 & \\
\hline$G A$ or $A A$ & $1.11(0.55-2.22)$ & 0.77 & $1.44(1.01-2.05)$ & 0.05 \\
\hline \multicolumn{5}{|l|}{ ER- $\beta$ rs4986938 } \\
\hline GG & 1 & & 1 & \\
\hline$G A$ & $1.30(0.82-2.05)$ & 0.26 & $1.08(0.85-1.35)$ & 0.54 \\
\hline$A A$ & $1.74(1.00-3.06)$ & 0.05 & $1.01(0.72-1.40)$ & 0.97 \\
\hline \multicolumn{5}{|l|}{ ER- $\beta$ rs 1271572} \\
\hline GG & 1 & & 1 & \\
\hline$T G$ & $1.12(0.72-1.74)$ & 0.63 & $1.19(0.94-1.51)$ & 0.15 \\
\hline$T T$ & $1.11(0.55-2.22)$ & 0.68 & $0.91(0.66-1.27)$ & 0.58 \\
\hline $\begin{array}{l}\text { ER- } \alpha \text {, oestrogen receptor } \alpha \text {; ER- } \beta \text {, o } \\
\text { a. Adjusted for age, education, cent } \\
\text { disorder. }\end{array}$ & physical limitations, $c 0$ & curre & orbidity, insomnia anc & ressive \\
\hline
\end{tabular}

have current severe depression, but this was at the limit of statistical significance. The other two ER- $\beta$ polymorphisms were not associated with late-life depression.

\section{Oestrogen receptor $\times$ hormone treatment interaction}

When the potential modifying effect of hormone treatment use on the association between these oestrogen receptor polymorphisms and severe depression in women was examined, there was a non-significant trend for an interaction between ER- $\beta$ rs1256049 and current hormone treatment (interaction term, $P=0.08$ in the multivariate adjusted model shown in Table 3). Subsequent analysis stratified by current hormone treatment use revealed that women who were not using treatment $(n=2986)$ were significantly more likely to have current severe depression with the $G A / A A$ genotype (odds ratio $(\mathrm{OR})=1.72,95 \%$ CI $1.17-2.50$, $P=0.005)$. In stark contrast, among women who were using hormone treatment $(n=539)$, the GA/AA genotype was not associated with the risk of severe depression $(\mathrm{OR}=0.69,95 \% \mathrm{CI}$ $0.23-2.08, P=0.51)$.

\section{Discussion}

In this older population-based cohort, we have found significant gender-specific associations between polymorphisms of ER- $\alpha$ and ER- $\beta$ with severe late-life depression. The results also provide some evidence of an interaction between hormone treatment and one of the ER- $\beta$ polymorphisms, which modified a woman's risk of depression.

\section{Association between ER- $\alpha$ polymorphisms and severe depression in women}

Of the few previous studies that have investigated the association between depression and ER- $\alpha$ polymorphisms in women, the results have been mixed, and this may relate to differences in study sizes (smaller studies may lack statistical power), and populations (e.g. age, menopausal status, hormone treatment use), as well as the criteria for depressive symptomatology. The SWAN study of 1538 pre- and perimenopausal women from four different ethnic groups ${ }^{25}$ and the Rotterdam study of 2468 elderly women, ${ }^{26}$ have both reported no significant association between the rs2234693 and rs9340799 polymorphisms and moderate depressive symptoms (CES-D $\geqslant 16$ ). In two small studies of young postmenopausal women, differential findings have been reported in unadjusted analysis. No association was found between these same ER- $\alpha$ polymorphisms and depressed mood in 177 Mexican women, ${ }^{6}$ yet significant associations were found in a study of 106 Korean women. ${ }^{27}$ The only previous study to examine the association between oestrogen receptor polymorphisms and major depressive disorder (based on the Hamilton Scale and DSM-IV criteria) reported that the frequency of the rs2234693 CC genotype was significantly higher in 126 midlife Chinese women with depression (mean age 46.7 years) than in the 89 controls. $^{28}$ In our larger study of 3525 elderly women however, the $C C$ and GG genotypes of the rs2234693 and rs9340799 polymorphisms respectively were associated with a significant decrease in current severe depression (defined as a current major depressive disorder based on DSM-IV criteria or severe depressive symptoms using a CES-D score of 23 or greater). In post hoc analysis we did not find a significant association with these ER- $\alpha$ polymorphisms and moderate depressive symptoms alone (CES-D $\geqslant 16$, see online Table DS1). Our findings thus relate specifically to a severe clinical level of current depression.

\section{Potential interaction between ER- $\beta$ polymorphism and hormone treatment}

The association between ER- $\beta$ and depression has been insufficiently studied. There is one report of a non-significant association between another polymorphism (rs1256030) and moderate depressive symptoms (CES-D $\geqslant 16$ ) in 1435 midlife women, ${ }^{25}$ and in a Korean study of 43 women with postmenopausal depression and 63 controls no significant association was found 
with rs1256049 or rs4986938. ${ }^{27}$ In our study we find that the ER- $\beta$ rs1256049 polymorphism was significantly associated with an increased likelihood of severe depression in women, but only for those who were non-hormone treatment users. No significant association was observed for women who were currently using hormone treatment. It has been shown previously that oestrogen receptor polymorphisms and hormone treatment can interact to influence health outcomes in women. ${ }^{15,17}$ To our knowledge, however, no study has examined whether such an interaction can modify the risk of depression, despite several randomised controlled trials demonstrating the psycho-protective effects of hormone treatment. ${ }^{4}$ Our finding provides some preliminary evidence that hormone treatment could be beneficial for certain genetically vulnerable women, by reducing the risk of depression associated with the ER- $\beta$ rs1256049 polymorphism.

\section{Oestrogen receptor polymorphisms and depression in men}

We found no significant association between ER- $\alpha$ polymorphisms and moderate or severe depression in men (Table 3 ), in accordance with the two previous studies that have been conducted. ${ }^{26,28}$ The rs2234693 and rs9340799 polymorphisms were not associated with major depressive disorder in a small case-control study of middle-aged Chinese $\operatorname{men}^{28}$ nor in the Rotterdam study of depressive symptoms. ${ }^{26}$ Neither of these studies, however, examined associations with ER- $\beta$. We report here that the $A A$ allele of the ER- $\beta$ rs4986938 may increase the likelihood of depression specifically in men, although this was of borderline significance. In a similar manner, one of the few prior studies examining this polymorphism reported a higher frequency of the $A$ allele in men with Alzheimer's disease, but no such association in women. ${ }^{29}$

\section{Biological hypothesis linking oestrogen receptors and depression}

The two oestrogeon receptors, ER- $\alpha$ and ER- $\beta$, classically function as ligand-activated transcription factors and can affect hundreds of genes, including regulation of the synthesis and metabolism of various neurotransmitters in the brain. ${ }^{2}$ The mechanisms by which oestrogen receptors could influence depression are thus complex. It remains uncertain what precise effects the polymorphisms examined here may have on receptor expression. Although silent mutations, they can still affect messenger RNA structure, stability and receptor synthesis, and thus have potentially important functional consequences. At least in terms of rs2234693 and rs9340799, they have been shown to regulate the expression of ER- $\alpha$ and they may alter transcription factor binding. ${ }^{15,30}$ These polymorphisms may also be in linkage disequilibrium with other functional polymorphisms that have not yet been identified. The ER- $\alpha$ polymorphisms examined in our study have been associated with other brain disorders, such as cognitive decline ${ }^{14}$ and Alzheimer's disease, ${ }^{7}$ although not consistently. These polymorphisms have also shown significant associations with oestradiol levels in postmenopausal women (lower oestradiol with the $T$ (rs2234693) and $A$ (rs9340799) alleles) ${ }^{20}$ and in a similar manner with bone density and fractures (higher bone mass density and lower fractures for the rs9340799 genotype $G G$ ) (see Ioannidis et al for meta-analysis ${ }^{18}$ ). This would support earlier findings that oestrogen may have a protective effect against depression. ${ }^{31}$

Our data suggest distinct genetic vulnerability to depression for men and women. Different polymorphisms of ER- $\beta$ increased the likelihood of severe depression in men and women, whereas in women, only ER- $\alpha$ polymorphisms were associated with late-life depression. There are numerous mechanisms that could help explain these gender differences (see Gillies \& McArthur for review $^{32}$ ). Although males and females have a similar distribution of ER- $\alpha$ and ER- $\beta$ in the brain, there appear to be differences in the level of expression of these receptors in various regions. Our results may partly account for gender differences in depression prevalence and highlight the need for a gender-specific approach to the development of novel hormone-based therapies.

\section{Study limitations and strengths}

Limitations to this study include the relatively low response rate, which limits the ability to generalise these findings as study volunteers tend to be better educated and healthier than the overall population. Participants diagnosed with probable/possible dementia at inclusion $(n=217)$ were excluded from this analysis to minimise recall bias. However, as such individuals may also have higher rates of depressive symptoms this could have decreased the overall power of the study, possibly underestimating the associations found. Possible prescription bias in relation to women who are given hormone treatment should also be taken into account, although we have controlled for numerous potential confounding factors in the analysis. The results of this analysis were not adjusted for multicomparisons, as there was a strong a priori biological rationale for investigating these five specific associations, given the extensive scientific literature supporting a role for oestrogen in depression. The usefulness of a Bonferroni correction in this study is thus questionable $\mathrm{e}^{33}$ and would result in an inflated type 2 error rate, especially given that the correction assumes independence of the tests, but both ER- $\alpha$ polymorphisms are in strong linkage disequilibrium, ${ }^{17}$ as are the three ER- $\beta$ polymorphisms. ${ }^{15}$ It remains likely, however, that based on the $5 \%$ significance level, one of the significant associations found occurred merely by chance. Finally, it should be noted that in this study we report associations between oestrogen receptor polymorphisms and the prevalence of late-life depression, but have not differentiated the independent associations with depression incidence and disease duration.

This study is strengthened by its sample size and populationbased design, as well as the inclusion of both men and women to enable the assessment of independent gender-specific associations. Depression was assessed by trained staff using two distinct measures, including a structured diagnostic interview, which have been validated in the general population. ${ }^{10}$ Severity ratings allowed us to examine separately the relationship between moderate depressive symptoms and severe depression, with oestrogen receptor genotypes. Although our analyses have adjusted for a large range of sociodemographic and health variables, including previous depressive episodes, it is still possible that there are unrecognised factors that could help explain our findings. Replication of our findings in other large population-based studies is needed.

We report here that polymorphisms of ER- $\alpha$ in particular are associated with depression in older women. In addition, there was some evidence that current hormone treatment modified the association between ER- $\beta$ rs1256049 and severe depression in women. These findings suggest the possibility that some women may be genetically more susceptible than others to the psycho-protective effects of hormone treatment. This could have important clinical applications, suggesting the potential for offering tailored hormonal therapies based on genetic markers for the treatment of mood disorders in women, and perhaps men, via the development of oestrogen-receptor selective effectors. 
Joanne Ryan, PhD, Inserm U1061 and Université Montpellier 1, Montpellier and Fondation FondaMental, Hopital Albert Chenevier, Creteil, France; Jacqueline Scal MSC, Isabelle Carrière, PhD, Inserm U1061 and Université Montpellier 1, Montpellier, France; Karine Peres, PhD, Inserm U897 and Université Bordeaux 2, Bordeaux, France; Olivier Rouaud, MD, Inserm U708, Paris, France; Pierre-Yves Scarabin MD, PhD, Inserm U1018, Université Paris Sud II, Villejuif, France; Karen Ritchie, PhD, MD, PhD, Inserm U1018, Université Paris Sud II, Villejuif, France; Karen Ritchie,
Inserm U1061 and Université Montpellier 1, Montpellier, France, and Faculty of Medicine, Imperial College, London, UK; Marie-Laure Ancelin, PhD, Inserm U1061 Montpellier and Université Montpellier 1, Montpellier, France

Correspondence: Joanne Ryan, Inserm U1061, Hôpital La Colombière, 39 Avenue Charles Flahault, BP 34493, 34093 Montpellier Cedex 5, France. Email: joanne.ryan@inserm.fr

First received 11 Jan 2011, final revision 22 Mar 2011, accepted 17 May 2011

\section{Funding}

The Three City (3C) study is conducted under a partnership agreement between the Institut National de la Santé et de la Recherche Médicale (Inserm), the Victor Segalen Bordeaux II University and Sanofi-Aventis. The Fondation pour la Recherche Médicale funded the preparation and first phase of the study. The $3 \mathrm{C}$ study is also supported by the Caisse preparation and first phase of the study. The $3 C$ study is also supported by the Caisse
Nationale Maladie des Travailleurs Salariés, Direction Génerale de la Santé, MGEN, Institut de la Longévité, Agence Française de Sécurité Sanitaire des Produits de Santé, the Regional Governments of Aquitaine, Bourgogne and Languedoc-Roussillon and, the Fondation de France, the Ministry of Research-Inserm Programme 'Cohorts and collection of biological material'. Part of this project is financed by grants from the Agence Nationale de la Recherche (projects ANR 2007-LVIE-004 and 2007-LVIE-005-01). J.R. received FondaMental-Servier grant from the Fondation FondaMental (France).

\section{Acknowledgements}

We thank the Génopôle of Lille, the Laboratories of Biochemistry of the University Hospitals of Dijon and Montpellier, the Town Council of Dijon and the Conseil Général of Côte d'Or.

\section{References}

1 Lopez-Leon S, Janssens AC, Gonzalez-Zuloeta Ladd AM, Del-Favero J, Claes SJ Oostra BA, et al. Meta-analyses of genetic studies on major depressive disorder. Mol Psychiatry 2008; 13: 772-85.

2 McEwen BS, Alves SE. Estrogen actions in the central nervous system. Endocr Rev 1999; 20: 279-307.

3 Ancelin ML, Scali J, Ritchie K. Hormonal therapy and depression: are we overlooking an important therapeutic alternative? J Psychosom Res 2007; 62: 473-85.

4 Soares CN, Almeida OP, Joffe H, Cohen LS. Efficacy of estradiol for the treatment of depressive disorders in perimenopausal women: a double-blind randomized, placebo-controlled trial. Arch Gen Psychiatry 2001; 58: 529-34.

5 Sowers MR, Jannausch ML, McConnell DS, Kardia SR, Randolph Jr JF. Endogenous estradiol and its association with estrogen receptor gene polymorphisms. Am J Med 2006; 119: S16-22.

6 Malacara JM, Perez-Luque EL, Martinez-Garza S, Sanchez-Marin FJ. The relationship of estrogen receptor-alpha polymorphism with symptoms and other characteristics in post-menopausal women. Maturitas 2004; 49: 163-9.

7 Corbo RM, Gambina G, Ruggeri M, Scacchi R. Association of estrogen receptor alpha (ESR1) Pvull and Xbal polymorphisms with sporadic Alzheimer's disease and their effect on apolipoprotein E concentrations. Dement Geriatr Cogn Disord 2006; 22: 67-72.

8 Lambert JC, Harris JM, Mann D, Lemmon H, Coates J, Cumming A, et al. Are the estrogen receptors involved in Alzheimer's disease? Neurosci Lett 2001; 306: 193-7.

9 The 3C Study Group. Vascular factors and risk of dementia: design of the three city study and baseline characteristics of the study population. Neuroepidemiology 2003; 22: 316-25.

10 Sheehan DV, Lecrubier $Y$, Sheehan $\mathrm{KH}$, Amorim $\mathrm{P}$, Janavs J, Weiller $\mathrm{E}$, et al The Mini-International Neuropsychiatric Interview (M.I.N.I.): the development and validation of a structured diagnostic psychiatric interview for DSM-IV and ICD-10. J Clin Psychiatry 1998; 59: 22-33; quiz 34-57.

11 American Psychiatric Association. Diagnostic and Statistical Manual of Mental Disorders (4th edn) (DSM-IV). APA, 1994.
12 Radloff L. The CES-D scale: a self-report depression scale for research in the general population. Appl Psychol Measurement 1977; 1: 385-401.

13 Radloff LS, Locke BZ. The community mental health assessment survey and the CES-D scale. In Community Surveys of Psychiatric Disorders (eds MM Weissman, JK Myers, CE Ross): 177-89. Rutgers University Press 1986

14 Yaffe K, Lui LY, Grady D, Stone K, Morin P. Estrogen receptor 1 polymorphisms and risk of cognitive impairment in older women. Biol Psychiatry 2002; 51: 677-82.

15 Herrington DM, Howard TD, Brosnihan KB, McDonnell DP, Li X, Hawkins GA, et al. Common estrogen receptor polymorphism augments effects of hormone replacement therapy on E-selectin but not C-reactive protein. Circulation 2002; 105: 1879-82.

16 Rexrode KM, Ridker PM, Hegener $\mathrm{HH}$, Buring JE, Manson JE, Zee RY Polymorphisms and haplotypes of the estrogen receptor-beta gene (ESR2) and cardiovascular disease in men and women. Clin Chem 2007; 53: 1749-56.

17 Silvestri S, Thomsen AB, Gozzini A, Bagger $Y$, Christiansen C, Brandi ML. Estrogen receptor alpha and beta polymorphisms: is there an association with bone mineral density, plasma lipids, and response to postmenopausal hormone therapy? Menopause 2006; 13: 451-61.

18 Ioannidis JP, Stavrou I, Trikalinos TA, Zois C, Brandi ML, Gennari L, et al. Association of polymorphisms of the estrogen receptor alpha gene with bone mineral density and fracture risk in women: a meta-analysis. $J$ Bone Miner Res 2002; 17: 2048-60.

19 Kjaergaard AD, Ellervik C, Tybjaerg-Hansen A, Axelsson CK, Gronholdt ML, Grande $P$, et al. Estrogen receptor alpha polymorphism and risk of cardiovascular disease, cancer, and hip fracture: cross-sectional, cohort, and case-control studies and a meta-analysis. Circulation 2007; 115: 861-71.

20 Schuit SC, de Jong FH, Stolk L, Koek WN, van Meurs JB, Schoofs MW, et al. Estrogen receptor alpha gene polymorphisms are associated with estradiol levels in postmenopausal women. Eur J Endocrinol 2005; 153: 327-34.

21 Lawton MP, Brody EM. Assessment of older people: self-maintaining and instrumental activities of daily living. Gerontologist 1969; 9: 179-86.

22 Katz S, Ford $A B$, Moskowitz RW, Jaffee MW. Studies of illness in the aged. The index of ADL: a standardized measure of biological and psychosocial function. JAMA 1963; 195: 94-9.

23 Folstein MF, Folstein SE, McHugh PR. 'Mini-mental state'. A practical method for grading the cognitive state of patients for the clinician. $J$ Psychiatr Res 1975; 12: 189-98

24 Jaussent I, Dauvilliers Y, Ancelin ML, Dartigues JF, Tavernier B, Touchon J, et al. Insomnia symptoms in older adults: associated factors and gender differences. Am J Geriatr Psychiatry 2010; 19: 88-97.

25 Kravitz HM, Janssen I, Lotrich FE, Kado DM, Bromberger JT. Sex steroid hormone gene polymorphisms and depressive symptoms in women at midlife. Am J Med 2006; 119: S87-93.

26 Tiemeier H, Schuit SC, den Heijer T, van Meurs JB, van Tuijl HR, Hofman A et al. Estrogen receptor alpha gene polymorphisms and anxiety disorder in an elderly population. Mol Psychiatry 2005; 10: 806-7.

27 Kim JJ, Pae CU, Kim MR, Min JA, Kim KH, Lee CU, et al. Association between estrogen receptor gene polymorphisms and depression in post-menopausal women: a preliminary study. Psychiatry Investig 2010; 7: 224-7.

28 Tsai SJ, Wang YC, Hong CJ, Chiu HJ. Association study of oestrogen receptor alpha gene polymorphism and suicidal behaviours in major depressive disorder. Psychiatr Genet 2003; 13: 19-22.

29 Pirskanen $M$, Hiltunen $M$, Mannermaa A, Helisalmi S, Lehtovirta M, Hanninen $T$, et al. Estrogen receptor beta gene variants are associated with increased risk of Alzheimer's disease in women. Eur J Hum Genet 2005; 13: 1000-6.

30 Maruyama $H$, Toji $H$, Harrington $C R$, Sasaki $K$, Izumi $Y$, Ohnuma $T$, et al. Lack of an association of estrogen receptor alpha gene polymorphisms and transcriptional activity with Alzheimer disease. Arch Neurol 2000; 57: 236-40.

31 Ryan J, Carriere I, Scali J, Ritchie K, Ancelin ML. Lifetime hormonal factors may predict late-life depression in women. Int Psychogeriatr 2008; 20 : 1203-18.

32 Gillies GE, McArthur S. Estrogen actions in the brain and the basis for differential action in men and women: a case for sex-specific medicines. Pharmacol Rev 2010; 62: 155-98.

33 Cardon LR, Bell Jl. Association study designs for complex diseases. Nat Rev Genet 2001; 2: 91-9. 